\title{
Prevalence and Risk Factors of Stress, Anxiety and Depression among Medical Students of a Private Medical University in Malaysia
}

\author{
Maher D Fuad ${ }^{1}$, Balsam Mahdi Nasir Al-Zurfi ${ }^{1}$, Mohammed Abdul Qader ${ }^{1}$, Mohammed Faez \\ Abu Bakar ${ }^{1}$, Maged Elnajeh ${ }^{1}$, Mohd Rusli Abdullah ${ }^{2}$ \\ ${ }^{1}$ Community Medicine Unit, ${ }^{2}$ Dean, International Medical School/Management and Science University, \\ Malaysia.
}

\begin{tabular}{ll}
\hline ARTICLE INFO \\
Received & $: 12 / 03 / 2015$ \\
Accepted & $: 13 / 04 / 2015$ \\
Published & $: 10 / 06 / 2015$
\end{tabular}

\section{KEYWORD}

Stress

Anxiety

Depression

Medical Students

DASS

Malaysia

\section{ABSTRACT}

Introduction: Medical school expected to be a time of personal development, achievement, and well-being. However, research shows that there are many negative effects on students' mental health due to the current educational process. Objective: This research aimed to determine the prevalence and risk factors of depression, anxiety, and stress among medical students of a private medical university in Malaysia. Method: Cross sectional study was conducted using self-administered questionnaires including socio-demographic factors, DASS-21 and MSSQ-40 questionnaires. Result: Prevalence of stress, anxiety, and depression were $46.9 \%, 76.2 \%$ and $60.2 \%$ respectively. Multiple logistic regression analysis showed that academic related stressors were only associated with stress [adjusted OR 1.78, 95\% CI $(1.23,2.58), p=0.002$ ]. Group activities related stressors were significantly associated with stress [adjusted $\mathrm{OR}=1.45$, $95 \% \mathrm{CI}(1.20,1.75), p<0.001$ ] and depression [adjusted OR $2.54,95 \% \mathrm{CI}$ $(2.01,3.20), p<0.001]$. On the other hand, derive and desire related stressors were significantly associated with stress [adjusted $\mathrm{OR}=1.76$, $95 \%$ CI $(1.28,2.58), p<0.001]$, anxiety [adjusted OR $2.54,95 \%$ CI $(2.01$, $3.20), p<0.001$ ], and depression [adjusted OR 2.54, 95\% C.I. (2.01, 3.20), $p<0.001$ ]. Indian students had increased anxiety [adjusted $\mathrm{OR}=2.25,95 \% \mathrm{CI}$ $(1.40,3.60), p=0.001]$. Availability of financial support protected against depression [adjusted OR=0.44, 95\% CI $(0.25,0.77), p=0.004])$. Similarly, fourth year medical students were at lower risk for developing anxiety [adjusted $\mathrm{OR}=0.43,95 \% \mathrm{CI}(0.25,0.75), p=0.003$ ] and depression [adjusted OR $0.59,95 \% \mathrm{CI}(0.36,0.97), p<0.036]$. Conclusion: Important risk factors were identified which will help in future development of stress management programs at the university.

(c) Medical Education Department, School of Medical Sciences, Universiti Sains Malaysia. All rights reserved.

CORRESPONDING AUTHOR: Dr. Maher D. Fuad Fuad, Head Community Medicine Unit, International Medical School, Management and Science University, University Drive, Off Persiaran Olahraga, Seksyen 13, 40100 Shah Alam, Selangor, Malaysia. Email: maherazawi@gmail.com

\section{Introduction}

Medical education aims to produce future doctors who are equipped with adequate knowledge, competency, in order to care for their patients, contribute to the development of the art of medicine, and to promote public health. Prospective medical professionals undergo highly selective procedures by the medical schools which aim to recruit brilliant and 
empathic students who are committed to these aims and willing to dedicate four years to establish them [1].

The U.S. and Canadian systems of medical education starts with students who have gained a bachelor's degree that minimally consists of basic training in biology, chemistry, and physics, as well as training in the humanities. Applicants usually have experience caring for patients through employment or volunteer work before joining medical school and must undergo comprehensive tests and a rigorous application and interview process. These processes are established to scrutinize individuals who intend to establish a future career in medicine. Once selected, medical schools and the students will work together to prepare students for a useful and fulfilling career at both individual and community levels [2].

Based on the above, we may expect that medical school would be a time of personal development, achievement, and well-being. However, research shows that there are many negative effect on students' mental health due to the current educational process which may have led to high prevalence of depression, anxiety, and stress among medical students [3]. It has also been theorized that burnout, a measure of distress common among residents and physicians in practice originates in medical school [1]. Many factors are thought to contribute to this decline in students' mental health including academic pressure, workload, financial concerns, sleep deprivation, exposure to patients' suffering and deaths, student and abuse [4]. Some have suggested that psychological distress among students may adversely influence their academic performance [5], contribute to academic dishonesty [6], and play a role in alcohol and substance abuse [7]. Student distress has also been reported to be associated with cynicism, an unwillingness to care for the chronically ill [8], and decreased empathy [9].

Psychological distress mainly depression is an increasing problem worldwide; the prevalence varies from country to country as well as from institution to another. Among those students with psychological disorders such as depression a very small percentage seeks treatment and only a fraction of them actually receives it. (Less than $25 \%$ of depression patients have access to psychiatric care and treatment in the world). Depression is predicted to be the leading cause of disease burden by 2030 [10]. Medical education, due to its structure, it is considered to be very stressful with a high proportion reaching up to $40 \%$ affected with psychological distress. Medical school is a time of significant psychological distress for physicians-in-training. Currently available information is insufficient to draw firm conclusions on the causes and consequences of student distress [11].

This study aimed to identify the prevalence of psychological distress (stress, anxiety and depression) among preclinical medical students and to explore the possible causes of stress by identifying the main stressor factors. The selection of the preclinical students is determined to identify the problem at an early stage in order to help the students to cope with their future stress in clinical years as the studies showed that the stress levels as persistent throughout the years of medical education as well as in physicians under training $[12,13]$.

\section{Method}

\section{Study design and population}

A cross sectional study to determine the prevalence and risk factors of psychological distress in medical students of a private University.

\section{Methods of data collection}

A questionnaire was distributed to the students which included 3 sections. Section one includes the demographic factors of the students and specific risk factors which include residence, accommodation, religion, financial support, and love relationship. Section two includes the DASS-21 questionnaire which is made of three domains namely stress, anxiety and depression. Section three includes the MSSQ-40 questionnaire which was used to determine the stressors that affect the students. Using the MSSQ [14], the stressors will be grouped into 6 
main domains namely: 1) Academic related stressor, 2) Inter/Intrapersonal Related Stressor, 3) Teaching and Learning Related Stressor, 4) Social Related Stressor, 5) Drive \& Desire Related Stressor, and 6) Group Activities Related Stressor.

\section{Statistics}

Data were entered and analyzed using statistical packages for social sciences (SPSS) version 20. The distribution and frequencies were examined. The continuous variables were expressed as mean and standard deviation. The frequencies and percentages for categorical variables were described. Simple and multiple logistic regression were used to determine the risk factors of psychological distress.

\section{Result}

\section{Characteristics of subjects}

A total of 762 students were enrolled in the study. The response rate was $100 \%$. The mean age of the respondents was 22.24 years with a standard deviation of 2 years. Thirty four percent were preclinical students and $77 \%$ were female. Majority of the students were Malay (67\%). Most of the students live in urban area. 69\% were Muslims. Other factors are shown in table 1.

\section{Prevalence of Psychological distress}

Table 2: Prevalence of Psychological distress using DASS-21 $(n=743)$

\begin{tabular}{llcc}
\hline DASS & Category & n & Prevalence\% \\
\hline Depression & Yes & 447 & 60.2 \\
& No & 295 & 39.8 \\
Anxiety & Yes & 567 & 76.2 \\
& No & 177 & 23.8 \\
Stress & Yes & 347 & 46.9 \\
& No & 393 & 53.1 \\
\hline
\end{tabular}

Using DASS-21, the prevalence of stress was $46.9 \%$, anxiety was $76 \%$ and depression was $60 \%$ (Table 2).
Table 1: Respondent profile $(\mathrm{n}=762)$

\begin{tabular}{|c|c|c|}
\hline Variable & Mean (SD) & $\mathrm{N}(\%)$ \\
\hline Age & $22.24(2)$ & - \\
\hline \multicolumn{3}{|l|}{ Year of study } \\
\hline Year 1 & - & $152(20)$ \\
\hline Year 2 & - & $105(14)$ \\
\hline Year 3 & - & $193(25)$ \\
\hline Year 4 & - & $177(23)$ \\
\hline Year 5 & - & $135(18)$ \\
\hline \multicolumn{3}{|l|}{ Gender } \\
\hline Male & - & $175(23)$ \\
\hline Female & - & $587(77)$ \\
\hline \multicolumn{3}{|l|}{ Race } \\
\hline Malay & - & $510(66.9)$ \\
\hline Chinese & - & $32(4.2)$ \\
\hline Indian & - & $194(25.5)$ \\
\hline Others & - & $26(3.4)$ \\
\hline \multicolumn{3}{|l|}{ Batch } \\
\hline Pre-clinical & - & $257(33.7)$ \\
\hline Clinical & - & $505(66.3)$ \\
\hline \multicolumn{3}{|c|}{ Highest educational level } \\
\hline SPM/O-Level & - & $44(5.8)$ \\
\hline Matriculation & - & $473(62.4)$ \\
\hline Diploma & - & $59(7.8)$ \\
\hline Bachelor degree & - & $178(23.5)$ \\
\hline Other & - & $4(0.5)$ \\
\hline \multicolumn{3}{|l|}{ Religion } \\
\hline Islam & - & $527(69.2)$ \\
\hline Buddhist & - & $20(2.6)$ \\
\hline Hindu & - & $172(22.6)$ \\
\hline Christian & - & $44(5.6)$ \\
\hline \multicolumn{3}{|l|}{ Financial Support } \\
\hline Yes & - & $673(88.3)$ \\
\hline No & - & 89 (11.7) \\
\hline \multicolumn{3}{|l|}{ Relationship } \\
\hline Yes & - & $194(25.7)$ \\
\hline No & - & $560(74.3)$ \\
\hline
\end{tabular}

\section{Risk factors of psychological distress}

Univariate analysis of the risk factors of stress ,using simple logistic regression, shows that being a year 3 medical students associated with 1.65 increase in the odds of stress compared to year 1 [OR $1.65,95 \% \mathrm{CI}(1.07,2.55), P$-value 0.023]. All domains of the MSSQ-40 show a significant association with stress. Results are shown in table 3 . 
Table 3: Risk factors of stress using DASS-21 for medical students of MSU ( $n=743)$

\begin{tabular}{|c|c|c|c|c|}
\hline Variables & Categories & $\mathbf{O R}^{\mathbf{a}}$ & $95 \% \mathrm{CI}^{\mathrm{b}}$ & P value $^{c}$ \\
\hline \multirow{5}{*}{ Year of study } & Year 1 & 1 & - & 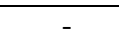 \\
\hline & Year 2 & 1.29 & $(0.78,2.14)$ & 0.317 \\
\hline & Year 3 & 1.65 & $(1.07,2.55)$ & 0.023 \\
\hline & Year 4 & 0.97 & $(0.63,1.51)$ & 0.906 \\
\hline & Year 5 & 0.79 & $(0.63,1.51)$ & 0.340 \\
\hline Age & - & 0.94 & $(0.88,1.00)$ & 0.061 \\
\hline \multirow[t]{2}{*}{ Gender } & Male & 1 & - & - \\
\hline & Female & 1.28 & $(0.91,1.81)$ & 0.158 \\
\hline \multirow[t]{2}{*}{ Batch } & Pre-clinical & 1 & - & - \\
\hline & Clinical & 1.02 & $(0.75,1.38)$ & 0.920 \\
\hline \multirow[t]{4}{*}{ Race } & Malay & 1 & - & - \\
\hline & Chinese & 1.004 & $(0.49,2.06)$ & 0.991 \\
\hline & Indian & 0.76 & $(0.68,1.33)$ & 0.758 \\
\hline & Others & 1.71 & $(0.75,3.87)$ & 0.201 \\
\hline \multirow[t]{5}{*}{ Highest educational level } & SPM/O-Level & 1 & - & - \\
\hline & Matriculation & 0.94 & $(0.50,1.78)$ & 0.846 \\
\hline & Diploma & 0.88 & $(0.39,1.97)$ & 0.747 \\
\hline & Bachelor degree & 0.95 & $(0.487,1.87)$ & 0.873 \\
\hline & Other & 0 & $(0.00, \mathrm{NA})$ & 0.999 \\
\hline \multirow{5}{*}{ Religion } & Islam & 1 & - & - \\
\hline & Buddhist & 0.92 & $(0.38,2.26)$ & 0.856 \\
\hline & Hindu & 0.96 & $(0.68,1.37)$ & 0.966 \\
\hline & Christian & 1.45 & $(0.70,2.97)$ & 0.315 \\
\hline & Others & 0.42 & $(0.11,1.61)$ & 0.206 \\
\hline \multirow[t]{2}{*}{ Financial Support } & No & 1 & - & - \\
\hline & Yes & 0.80 & $(0.51,1.26)$ & 0.337 \\
\hline \multirow[t]{2}{*}{ Love } & No & 1 & - & - \\
\hline & Yes & 0.93 & $(0.67,1.29)$ & 0.655 \\
\hline Academic related stress & - & 3.43 & $(2.65,4.43)$ & $<0.001$ \\
\hline Inter/Intrapersonal Related Stressor & - & 2.24 & $(1.86,2.70)$ & $<0.001$ \\
\hline $\begin{array}{l}\text { Teaching and Learning Related } \\
\text { Stressor }\end{array}$ & - & 2.55 & $(2.05,3.18)$ & $<0.001$ \\
\hline Social Related Stressor & - & 2.82 & $(2.21,3.58)$ & $<0.001$ \\
\hline Drive \& Desire Related Stressor & - & 2.07 & $(1.76,2.44)$ & $<0.001$ \\
\hline Group Activities Related Stressor & - & 2.99 & $(2.42,3.71)$ & $<0.001$ \\
\hline
\end{tabular}

Regarding anxiety, Univariate analysis, using simple logistic regression, shows that all the domains of the MSSQ-40 have a significant association with anxiety. Also being in clinical years shows a $50 \%$ reduction in the odds of anxiety. Results are shown in table 4.

Table 4: Risk factors of anxiety using DASS-21 for medical students of MSU ( $n=743)$

\begin{tabular}{llccc}
\hline Variables & Categories & $\mathbf{O R}^{\mathbf{a}}$ & $\mathbf{9 5 \%} \mathbf{C I}^{\mathbf{b}}$ & $\mathbf{P ~ V a l u e}^{\mathbf{c}}$ \\
\hline Year of study & Year 1 & 1 & - & - \\
& Year 2 & 1.58 & $(0.79,3.15)$ & 0.197 \\
& Year 3 & 1.40 & $(0.79,2.50)$ & 0.246 \\
& Year 4 & 0.46 & $(0.27,0.76)$ & 0.002 \\
Age & Year 5 & 0.49 & $(0.27,0.76)$ & 0.010 \\
Gender & - & 0.92 & $(0.85,0.99)$ & 0.020 \\
& Male & 1 & - & - \\
Batch & Female & 1.28 & $(0.87,1.28)$ & 0.215 \\
& Pre-clinical & 1 & - & - \\
Race & Clinical & 0.56 & $(0.38,0.82)$ & 0.003 \\
& Malay & 1 & - & - \\
& Chinese & 1.22 & $(0.52,2.91)$ & 0.648 \\
& Indian & 1.53 & $(1.006,2.323)$ & 0.047 \\
& Others & 2.74 & $(0.81,9.26)$ & 0.106 \\
\hline
\end{tabular}

${ }^{\mathrm{a}}$ Odds ratio, ${ }^{\mathrm{b}} 95 \%$ Confidence Interval, ${ }^{\mathrm{c}}$ Simple Logistic Regression Analysis 
Table 4: Continued

\begin{tabular}{|c|c|c|c|c|}
\hline Variables & Categories & $\mathbf{O R}^{\mathbf{a}}$ & $95 \% \mathrm{CI}^{\mathrm{b}}$ & P Valuec \\
\hline \multirow[t]{5}{*}{ Highest educational level } & SPM/O-Level & 1 & - & - \\
\hline & Matriculation & 1.79 & $(0.91,3.52)$ & 0.090 \\
\hline & Diploma & 1.48 & $(0.62,3.57)$ & 0.379 \\
\hline & Bachelor degree & 1.27 & $(0.62,2.60)$ & 0.519 \\
\hline & Other & 0.48 & $(0.06,3.79)$ & 0.489 \\
\hline \multirow{5}{*}{ Religion } & Islam & 1 & - & - \\
\hline & Buddhist & 2 & $(0.58,6.92)$ & 0.275 \\
\hline & Hindu & 1.56 & $(1.004,2.431)$ & 0.048 \\
\hline & Christian & 2.47 & $(0.85,7.16)$ & 0.097 \\
\hline & Others & 0.42 & $(0.13,1.41)$ & 0.161 \\
\hline \multirow[t]{2}{*}{ Financial Support } & No & 1 & - & - \\
\hline & Yes & 0.80 & $(0.51,1.26)$ & 0.337 \\
\hline \multirow[t]{2}{*}{ Love } & Yes & 1 & - & - \\
\hline & No & 1.03 & $(0.70,1.52)$ & 0.871 \\
\hline Academic related stress & - & 3.10 & $(2.37,4.05)$ & $<0.001$ \\
\hline Inter/Intrapersonal Related Stressor & - & 2.23 & $(1.80,2.77)$ & $<0.001$ \\
\hline $\begin{array}{l}\text { Teaching and Learning Related } \\
\text { Stressor }\end{array}$ & - & 2.34 & $(1.85,2.96)$ & $<0.001$ \\
\hline Social Related Stressor & - & 3.30 & $(2.49,4.38)$ & $<0.001$ \\
\hline Drive \& Desire Related Stressor & - & 1.89 & $(1.56,2.30)$ & $<0.001$ \\
\hline Group Activities Related Stressor & - & 2.45 & $(1.97,3.06)$ & $<0.001$ \\
\hline
\end{tabular}

Table 5: Risk factors of Depression using DASS-21 for medical students of MSU ( $n=743$ )

\begin{tabular}{|c|c|c|c|c|}
\hline Variables & Categories & $\mathbf{O R}^{\mathrm{a}}$ & $95 \% \mathrm{CI}^{\mathrm{b}}$ & P Value \\
\hline \multirow[t]{5}{*}{ Year of study } & Year 1 & 1 & - & - \\
\hline & Year 2 & 1.57 & $(0.919,2.69)$ & 0.099 \\
\hline & Year 3 & 1.22 & $(0.78,1.92)$ & 0.377 \\
\hline & Year 4 & 0.61 & $(0.39,0.95)$ & 0.028 \\
\hline & Year 5 & 0.88 & $(0.55,0.95)$ & 0.603 \\
\hline Age & - & 0.97 & $(0.91,1.04)$ & 0.361 \\
\hline \multirow[t]{2}{*}{ Gender } & Male & 1 & - & - \\
\hline & Female & 0.99 & $(0.70,1.40)$ & 0.946 \\
\hline \multirow{2}{*}{ Batch } & Pre-clinical & 1 & - & - \\
\hline & Clinical & 0.73 & $(0.53,0.99)$ & 0.047 \\
\hline \multirow[t]{4}{*}{ Race } & Malay & 1 & - & - \\
\hline & Chinese & 0.74 & $(0.36,1.52)$ & 0.417 \\
\hline & Indian & 1.02 & $(0.72,1.44)$ & 0.916 \\
\hline & Others & 1.05 & $(0.47,2.36)$ & 0.908 \\
\hline \multirow[t]{5}{*}{ Highest educational level } & SPM/O-Level & 1 & - & - \\
\hline & Matriculation & 0.85 & $(0.44,1.65)$ & 0.633 \\
\hline & Diploma & 0.67 & $(0.29,1.52)$ & 0.335 \\
\hline & Bachelor degree & 0.88 & $(0.44,1.78)$ & 0.726 \\
\hline & Other & 0.19 & $(0.02,1.94)$ & 0.159 \\
\hline \multirow{5}{*}{ Religion } & Islam & 1 & - & - \\
\hline & Buddhist & 1.002 & $(0.40,2.49)$ & 0.997 \\
\hline & Hindu & 1.09 & $(0.76,1.55)$ & 0.655 \\
\hline & Christian & 1.47 & $(0.68,3.17)$ & 0.326 \\
\hline & Others & 0.17 & $(0.04,0.79)$ & 0.024 \\
\hline \multirow[t]{2}{*}{ Financial Support } & No & 1 & - & - \\
\hline & Yes & 0.50 & $(0.30,0.82)$ & 0.006 \\
\hline \multirow[t]{2}{*}{ Love } & Yes & 1 & - & - \\
\hline & No & 1.03 & $(0.73,1.44)$ & 0.869 \\
\hline Academic related stress & - & 2.43 & $(1.93,3.06)$ & $<0.001$ \\
\hline Inter/Intrapersonal Related Stressor & - & 2.02 & $(1.68,2.43)$ & $<0.001$ \\
\hline $\begin{array}{l}\text { Teaching and Learning Related } \\
\text { Stressor }\end{array}$ & - & 2.28 & $(1.85,2.81)$ & $<0.001$ \\
\hline Social Related Stressor & - & 2.62 & $(2.06,3.33)$ & $<0.001$ \\
\hline Drive \& Desire Related Stressor & - & 2.16 & $(1.82,2.57)$ & $<0.001$ \\
\hline Group Activities Related Stressor & - & 2.45 & $(2.01,3.00)$ & $<0.001$ \\
\hline
\end{tabular}


Univariate analysis for risk factors of depression using simple logistic regression shows that students in clinical years are protected against depression [OR 0.73 , 95\% C.I. 0.53, 0.99), $P$ value <0.047]. Similarly, having financial support also protect against depression [OR 0.50, 95\% C.I. (0.30, 0.82), P-value 0.006]. Similar to stress and anxiety, all the domains of MSSQ-40 show a significant association with depression (Table 5).

Multiple logistic regression analysis (table 6) showed that academic related stressors were only associated with stress [adjusted OR 1.78, 95\% CI (1.23, 2.58), $p=0.002]$. Group activities related stressors were significantly associated with stress [adjusted $\mathrm{OR}=1.45,95 \% \mathrm{CI} \quad(1.20,1.75)$, $p<0.001$ ] and depression [adjusted OR 2.54, 95\% CI $(2.01,3.20), p<0.001]$. On the other hand, derive and desire related stressors were significantly associated with stress [adjusted $\mathrm{OR}=1.76,95 \% \mathrm{CI}(1.28,2.58), p<0.001]$, anxiety [adjusted OR 2.54, 95\% CI (2.01, 3.20), $p<0.001$ ], and depression [adjusted OR 2.54, $95 \%$ CI $(2.01,3.20), p<0.001]$. Indian students had increased anxiety [adjusted $\mathrm{OR}=2.25,95 \%$ CI(1.40, 3.60), $p=0.001]$. Availability of financial support protected against depression [adjusted $\mathrm{OR}=0.44,95 \%$ CI $(0.25,0.77)$, $p=0.004]$. Similarly, fourth year medical students were at lower risk for developing anxiety [adjusted $\mathrm{OR}=0.43,95 \% \mathrm{CI}(0.25,0.75)$, $p=0.003$ ] and depression [adjusted $\mathrm{OR}=0.59$, $95 \%$ CI $(0.36,0.97), p<0.036]$.

Table 6: Risk factors of stress, anxiety and depression using DASS-21 for medical students of MSU ( $n=743$ )

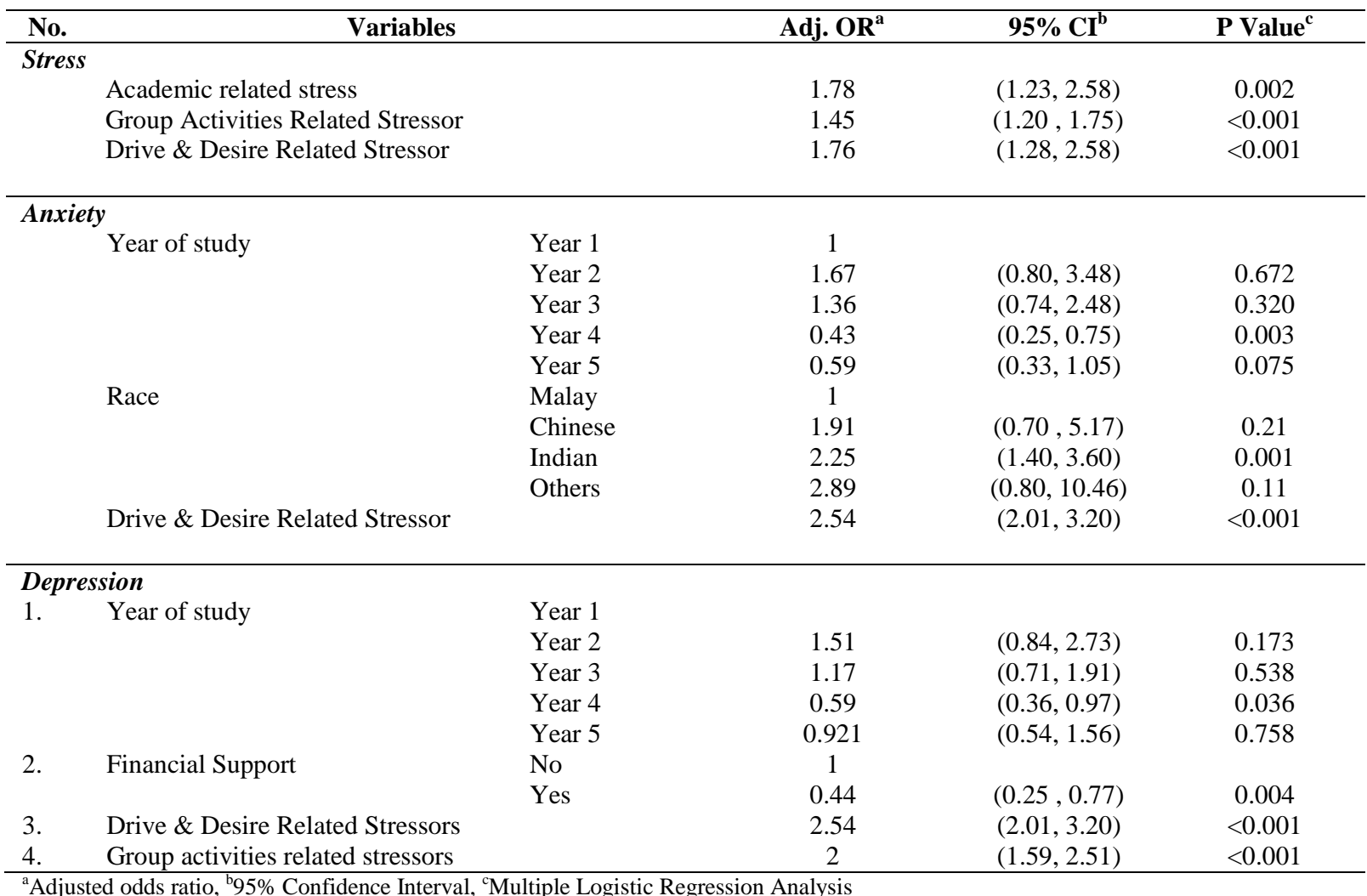

\section{Discussion}

This study shows that there is a considerable amount of stress, anxiety and depression in medical students. This is similar to other studies conducted in other Malaysian universities as well as in other parts of the world [15-19].
Prevalence of stress was $47 \%$ which is higher than that reported by Maher et al [19] which reported $17 \%$. The reason for this could be related to a program held by UPM to enhance the students coping strategies toward stress which is usually conducted at the end of year 1 . 
Our study shows that the main risk factors that contribute to stress include academic related stress, group activities related stressor, and drive $\&$ desire related stressor. Group activities related stressors were also identified as one of the risk factors by the study conducted in UPM [19].

The prevalence of anxiety was $76 \%$ which is supported by the finding of another study conducted in Pakistan, Karachi [20] and another conducted in USM in 2012 [21]. After controlling for confounders the main factors contributing to anxiety among the medical students of drive and desire related stressors, and Indian race. On the other hand year 4 and 5 students are protected against anxiety which could be due to maturation of the students.

Depression ,on the other hand, had a prevalence of $60 \%$ which is similar to that reported by Inam et al. [22]. The main factors that seem to contribute to depression in our study include derive and desire related stressor, and group activities related stressor and not having a financial support. Similar to anxiety, year 4 and 5 students seems to be protected when compared to year 1 .

Group activities related stressor found to be as a major factor contributing to the students' mental health which needs further exploration and research to identify their role.

The generalizability of the study results is limited by the characteristics of the sample and we would recommend a major study that includes more than one university to be conducted to further examine the risk factors of stress, anxiety and depression in order to find a proper and generalized solution suitable for Malaysian students.

\section{Conclusion}

In this study, the need for complete and integrated strategy to prevent medical students' negative psychological problems has been highlighted. Although the prevalence is based on a screening tools (i.e. questionnaires), it does not affect the importance for further exploration and further research to improve self-reported negative emotion by the future medical professionals. A comprehensive collaboration between stakeholders in the government and medical schools should be implemented in order to improve medical students' psychological health.

\section{Acknowledgement}

The authors would like to thank Management and Science University for approving the study and special thanks to year 4 MBBS students for helping in collecting the data.

\section{Reference}

1. Dyrbye LN, Thomas MR, Shanafelt TD. Systematic review of depression, anxiety, and other indicators of psychological distress among U.S. and Canadian medical students. Acad Med, 2006;81(4):354-73.

2. Colleges AOAM and LCOM. Education, Functions and structure of a medical school: standards for accreditation of medical education programs leading to the MD degree 2003: Liaison Committee on Medical Education.

3. Mohd Sidik S, Rampal L, Kaneson N. Prevalence of emotional disorders among medical students in a Malaysian university. Asia Pacific Family Medicine, 2003; 2(4): 213-217.

4. Yusoff MSB, Rahim AFA. The Medical Student Stressor Questionnaire (MSSQ) Manual. 2010.

5. Stewart SM et al. A prospective analysis of stress and academic performance in the first two years of medical school. Med Educ, 1999;33(4):243-50.

6. Hojat $M$ et al. Students' psychosocial characteristics as predictors of academic performance in medical school. Acad Med, 1993. 68(8):635-7.

7. Baldwin DC Jr et al., Substance use among senior medical students. A survey of 23 medical schools. JAMA, 1991;265(16): 2074-2078.

8. Crandall SJ, Volk RJ, Loemker V. Medical students' attitudes toward providing care for the underserved - Are we training socially responsible physicians? JAMA, 1993; 269(19): 2519-2523. 
9. Hojat, M., et al., An empirical study of decline in empathy in medical school. Med Educ, 2004. 38(9): p. 934-41.

10. World Federation for Mental Health. Depression: A Global Crisis, 2012.

11. Brennan $\mathrm{J}$ et al. Stress management intervention for first year medical students. Annals of Behavioral Science and Medical Education, 2010;16(2):15-19.

12. Yusoff MSB, Rahim AFA, Yaacob MJ. Prevalence and sources of stress among Universiti Sains Malaysia medical students. Malays J Med Sci, 2010;17(1): 30-37.

13. Yusoff MSB, Rahim AFA. Prevalence and sources of stress among postgraduate medical trainees: initial findings. ASEAN Journal of Psychiatry, 2010;11(2):180-189.

14. Yusoff MSB, Rahim AFA, Yaacob MJ. The development and validity of the Medical Student Stressor Questionnaire (MSSQ). ASEAN Journal of Psychiatry, 2010;11(1): 13-24.

15. Sherina M, Kaneson N. The prevalence of depression among medical students. Malaysian Journal of Psychiatry, 2003; 11(1):12-17.

16. Liew YY, Yusoff MSB. Prevalence and sources of stress among medical students in Universiti Sains Malaysia and Universiteit Maastricht. Education in Medicine Journal, 2013;5(4):34-41

17. Zaid Z, Chan S, Ho J, Emotional disorders among medical students in a Malaysian private medical school. Singapore Medical Journal, 2007;48(10): 895-899.

18. Yusoff MSB, Rahim AFA, and Yaacob MJ. The prevalence of final year medical students with depressive symptoms and its contributing factors. International Medical Journal, 2011;18(4):305-309.

19. Maher DFF; Lye MS, N.I., Ismail SI, Kar PC. Prevalence and risk factors of Stress, Anxiety and Depression among Preclinical Medical students in Universiti Putra Malaysia in 2014 International Journal of Collaborative Research on Internal Medicine \& Public Health, 2015;7(1).

20. Khan MS et al. Prevalence of depression, anxiety and their associated factors among medical students in Karachi, Pakistan. Journal-Pakistan Medical Association, 2006; 56(12):583.

21. Yusoff MSB, et al. Prevalence and associated factors of stress, anxiety and depression among prospective medical students. Asian journal of psychiatry, 2013; 6(2):128-133.
22. Inam SN, Saqib A, Alam E. Prevalence of anxiety and depression among medical students of private university. J Pak Med Assoc, 2003. 53(2): p. 44-7. 